\title{
Non-small cell lung cancer therapy: safety and efficacy in the elderly
}

This article was published in the following Dove Press journal:

Drug, Healthcare and Patient Safety

18 April 2013

Number of times this article has been viewed

\author{
Owen S Glotzer' \\ Thomas Fabian' \\ Anurag Chandra ${ }^{2}$ \\ Charles T Bakhos ${ }^{2}$ \\ 'Division of Thoracic Surgery, Albany \\ Medical Center, Department of \\ Surgery, Albany Medical College, \\ Albany, New York, USA; 'Department \\ of Radiation Oncology, Albany Medical \\ Center, Albany Medical College, \\ Albany, New York, USA
}

Background: Our objective was to evaluate and review the current literature on the treatment of non-small cell lung cancer (NSCLC) in the elderly.

Methods: We selected recent peer-reviewed articles addressing ageing, cancer treatment in the elderly, and lung cancer treatment in the elderly. We defined elderly as over the age of 70.

Results: The population is ageing dramatically throughout most of the world. Given that situation, clinicians are seeing and being asked to treat more elderly patients that have NSCLC. Elderly patients are less likely to participate or be allowed to participate in prospective or retrospective studies of treatments for NSCLC. Elderly patients are also less likely to be staged appropriately for their advanced tumors, and are less likely to be referred for surgery or adjuvant therapy after surgery. When treatment is tailored to patient comorbidities but not to age, the data support survival and outcomes comparable to those of younger patients.

Conclusions: Data are limited on the treatment of elderly patients with NSCLC. No data exist to support limiting recommendations for treatment based on age alone. Treatments should be determined on an individual basis.

Keywords: thoracic surgery, radiation therapy, chemotherapy, pulmonary, physiology, ageing, SBRT

\section{Introduction}

Lung cancer is the second most common malignancy in the developed world, having a median age of diagnosis occurring at 70 years of age. ${ }^{1,2}$ Since the end of World War II, there has been a dramatic expansion in the world's population; in addition to the post-war generation of baby boomers, advances in health and healthcare delivery have led to increased life expectancy. The United Nations 2002 World Assembly on Ageing stated that the ageing population was unprecedented and was a global phenomenon. ${ }^{3}$ Lung cancer will likely mirror this ageing population expansion, and increasing numbers of these patients will require clinicians to familiarize themselves with agerelated issues and cancer-treatment delivery.

Elderly is a relative term, but in the context of this paper, it shall include patients over the age of 70 . The authors concede the importance of distinguishing between chronologic age and biologic age. Although no formula exists to calculate biologic age, it is generally accepted to be chronologic age plus comorbidities. In healthy individuals, it is chronologic age minus a better-than-expected functional status.

Most researchers agree that age-related issues do influence the clinician's evaluation of the elderly patient. Although age should be considered in the assessment of a patient, it is likely that common misconceptions regarding these patients 
may influence treatment recommendations. Quality of life, long-term outlook, and survival in this population can be perceived incorrectly. These misperceptions can then influence treatment decisions. A better understanding of how age affects prognosis, treatment options, and outcomes is necessary, to avoid the undertreatment of this select population. This manuscript attempts to review relevant epidemiologic figures, the normal physiologic consequences of ageing, and outcome data from surgical, chemotherapy, and radiation treatments.

\section{The ageing population and treatment bias}

According to the 2010 US Census Bureau, the population over the age of 65 is $13.0 \%$ of the total population. ${ }^{4}$ This represents a $15.1 \%$ increase in comparison to the 2000 Census Bureau report. The 2010 report noted that the population aged $45-64$ increased by $31.5 \%$ over the same 10 -year period, and suggested that the percentage of elderly would continue to increase. According to the same report, the life expectancy in the US was 77.6 years, and the mean life expectancy for an 80-year-old individual was nearly 9 years. The expected number of deaths per 1000 80-year-old individuals was only 30 per annum. ${ }^{5}$ Similar data are seen throughout developed countries. Worldwide, the median life expectancy varies widely, but was estimated to be 67.2 years in $2010 .^{3}$

Ageism in healthcare is generally the result of a lack of awareness as it relates to the prognosis of cancer, lack of awareness of life expectancy, or misconceptions regarding the quality of life the elderly can enjoy.
As shown in Table 1, research and statistics contradict the idea that the elderly have a limited life expectancy. It is therefore important for physicians to be aware of the duration of life of an elderly patient when developing a treatment regimen. In fact, these statistics depict the older individual as being likely to enjoy a life course extending beyond what is typically perceived by physicians. It is then imperative that these elderly patients be treated with the intent to fulfill their life expectancy and aim to maintain and improve their quality of life.

To illustrate this age misconception, Leonard et $\mathrm{al}^{6}$ investigated the "attitudes" and "perceptions" breast cancer specialists have regarding the management of elderly patients with breast cancer. In this 2010 study, only $61 \%$ of respondents were confident that they could evaluate the elderly patients' needs, and $41 \%$ of them said age discrimination was a "recognized problem." When asked about perceptions of treatment, $92 \%$ of these specialists stated that the elderly were at risk of exclusion from chemotherapy, $42 \%$ from axillary node assessment, and $41 \%$ from adjuvant radiotherapy following breast-conserving surgery. ${ }^{6}$ Similarly, in the treatment of non-small cell lung cancer (NSCLC), few adjuvant trials include patients over 75 years of age, and referral patterns seem to be influenced by this factor. In fact, Kassam et al evaluated referral patterns for resected NSCLC and found that surgeons were less likely to refer patients based on age considerations. $^{7}$ These indirect data suggest that elderly individuals with lung cancer are less likely to be fully treated. However, various studies have shown there are a variety of methods that can be employed to successfully treat elderly patients with NSCLC. ${ }^{8-10}$

Table I Period life table, or calculated life expectancy, of individuals aged 75-90 years in the United States in 2007

\begin{tabular}{lllllll}
\hline Age & $\begin{array}{l}\text { Death probability } \\
\text { (male) }\end{array}$ & $\begin{array}{l}\text { Number of lives } \\
\text { (male) }\end{array}$ & $\begin{array}{l}\text { Life expectancy } \\
\text { (male) }\end{array}$ & $\begin{array}{l}\text { Death probability } \\
\text { (female) }\end{array}$ & $\begin{array}{l}\text { Number of lives } \\
\text { (female) }\end{array}$ & $\begin{array}{l}\text { Life expectancy } \\
\text { (female) }\end{array}$ \\
\hline 75 & 0.040010 & 61,612 & 10.62 & 0.027709 & 73,679 & 12.55 \\
76 & 0.043987 & 59,147 & 10.04 & 0.030659 & 71,638 & 11.90 \\
77 & 0.048359 & 56,545 & 9.48 & 0.033861 & 69,441 & 11.26 \\
78 & 0.053140 & 53,811 & 8.94 & 0.037311 & 67,090 & 10.63 \\
79 & 0.058434 & 50,951 & 8.41 & 0.041132 & 64,587 & 10.03 \\
80 & 0.064457 & 47,974 & 7.90 & 0.045561 & 61,930 & 9.43 \\
81 & 0.071259 & 44,882 & 7.41 & 0.050698 & 59,109 & 8.86 \\
82 & 0.078741 & 41,683 & 6.94 & 0.056486 & 56,112 & 8.31 \\
83 & 0.086923 & 38,401 & 6.49 & 0.062971 & 52,942 & 7.77 \\
84 & 0.095935 & 35,063 & 6.06 & 0.070259 & 49,608 & 7.26 \\
85 & 0.105937 & 31,699 & 5.65 & 0.078471 & 46,123 & 6.77 \\
86 & 0.117063 & 28,341 & 5.26 & 0.087713 & 42,504 & 6.31 \\
87 & 0.129407 & 25,024 & 4.89 & 0.098064 & 38,776 & 5.87 \\
88 & 0.143015 & 21,785 & 4.55 & 0.109578 & 34,973 & 5.45 \\
89 & 0.157889 & 18,670 & 4.22 & 0.122283 & 31,141 & \\
90 & 0.174013 & 15,722 & 3.92 & 0.136190 & 27,333 & \\
\hline
\end{tabular}




\section{Physiologic ageing}

Normal ageing affects the physiology of all the body's systems, the effects of which are important in assessing various treatment options. Certainly, the older patient appears to be less physiologically resilient to surgical insult than is the younger patient, but this does not support withholding surgical treatment pathways based on age alone.

The physiologic consequences of ageing are well established. The organ systems easiest to evaluate in the elderly are the neurocognitive and musculoskeletal systems, and these evaluations should influence recommendations based on quality of life issues. Alternatively, the organ systems that are more likely to predict tolerance of treatment options are the cardiovascular, respiratory, and hepatorenal systems. In these organ systems, there are well known physiologic derangements associated with ageing that influence the care that can be delivered.

\section{Cardiovascular}

Cardiac function undergoes a fairly consistent decline over an individual's lifetime. Cardiac output declines steadily, losing about $1 \%$ per year once the individual reaches his or her thirties; this will occur in the absence of pathology. ${ }^{11}$ There are a number of factors that likely contribute to this decline in cardiac function; one that has been repeatedly noted is the decline in maximum heart rate associated with advancing age. ${ }^{12}$ Additionally, cardiac muscle has a decreased inotropic response to catecholamines and glycosides. ${ }^{13}$ As a person ages, there is also a progressive stiffening of the walls of arteries. ${ }^{12,14}$ These changes increase one's risk of all cardiac events.

\section{Respiratory}

All of the previously mentioned cardiac affects lead to a number of physiologic changes on the organ-system and organismal levels. A decreased maximum oxygen uptake is seen with normal ageing. ${ }^{15}$ Additionally, arterial oxygen pressure decreases consistently with age, which coincides with a decreased closing volume of the lung, as well as impaired elasticity. ${ }^{16}$

Although the total lung volume remains consistent over the course of an individual's life, vital capacity undergoes a steady decline. This indicates that there is an increase in residual volume in the lung, the majority of which develops after the age of $40 .{ }^{13}$ This is at least partially responsible for the decreased maximum expiratory flow rates and maximum voluntary ventilation. ${ }^{13,17}$ It appears that the decline in the lungs elastic recoil is the most physiologically apparent change that is a direct result of ageing. This is a consistent decline that equally affects men and women, after lung volume has been accounted for. ${ }^{18}$

\section{Hepatorenal}

Studies have shown that there is an increased distribution of orally administered propranolol to the tissues in the aged individual. This indicates a decreased first pass effect, and an overall decrease in hepatic metabolism. ${ }^{19}$ The kidneys slowly atrophy to upwards of $30 \%$ by the ninth decade of life. Plasma creatinine concentrations maintain a level of consistency throughout life. ${ }^{13,20}$ However, the glomerular filtration rate declines markedly with age. This indicates a likely drop in the production of creatinine from an ageing muscular system. ${ }^{20}$ It appears that variable changes take place across individual portions of the nephron. For example, sodium excretion appears to maintain consistency, whereas lithium clearance has been found to show a marked decrease in the elderly. This indicates that the distal tubule is more affected by ageing than the proximal tubule. ${ }^{20}$

Despite the age-related reduction in function of these organ systems, ultimate decisions regarding the systems' ability to tolerate therapy or not is determined by objective testing, which is the same regardless of the patient's age. This applies, for example, to the choice of chemotherapy in a patient with limited creatinine clearance, or to the surgical considerations when the patient's pulmonary function is adequate. As such, the determinants related to treatment are the same regardless of age.

\section{Surgery}

While surgery usually offers the best chance of cure in early-stage lung cancer, historically, it has been underused in elderly patients, with the thought that thoracotomy carries a prohibitive risk to this patient population. ${ }^{21}$ This was confirmed in a few reports many decades ago, including the Lung Cancer Study Group ${ }^{22}$ data, which found a higher mortality rate in older patients compared to younger ones. There was a 30 -day mortality of $7.1 \%$ in patients older than 70 years, compared to $1.3 \%$ in patients $60-69$ years, and $0.4 \%$ for patients younger than 60 years. A statistically significant difference was found between patients younger than 60, compared with those aged 60-69 $(P<0.01)$, as well as between patients aged 60-69, compared with those older than 70 years $(P=0.047) .{ }^{22}$

Since then, significant advances in surgical techniques, post-operative care, and adjuvant treatment have been achieved, resulting in decreased morbidity and mortality after 
lung resection. For instance, Wada and colleagues, in 1998, published a one-year Japanese experience with lung resection through a thoracotomy in more than 7000 patients; they reported a 30 -day mortality of $0.4 \%$ for patients younger than 60 years, $1.3 \%$ for patients between the ages of 60 and 69 , $2 \%$ for those aged 70 to 79 years, and $2.2 \%$ for those above 80 years of age. ${ }^{23}$ Furthermore, this recent trend in lower mortality after lung resection was confirmed after the emergence of minimally invasive approaches, especially video-assisted thoracic surgery (VATS). The reported benefits of VATS over thoracotomy in the published literature range from reduced postoperative pain and narcotics usage to a shorter hospital stay, a quicker return to preoperative activities, and better preservation of lung function. ${ }^{24-26}$

These physiologic advantages can at least in part explain the lower morbidity and mortality reported by many authors after VATS lung resection. Jaklitsch and colleagues reported a less than $1 \%$ thirty-day mortality rate in their series of 296 patients (age $>65$ years) who underwent 307 VATS procedures; their median length of stay was 4 days for patients aged 65 to 79, and 5 days for those aged 80-90. Of note, though, was that only 32 out of the 307 procedures involved anatomic resections (lobectomy or segmentectomy). ${ }^{27}$ Reflecting the benefits of the minimally invasive approach and the increasing incidence of lung cancer in an ageing population, McKenna and colleagues reported a $0.8 \%$ mortality rate in a series of 1100 VATS lobectomies, where the average age was 71.2 years. ${ }^{28}$ While this report, and many others like it, demonstrate the feasibility, safety, and advantages of VATS lung resection in the management of NSCLC in the elderly, they also refute the initial doubts that were raised around a potential oncological compromise that could affect survival outcomes. ${ }^{29}$

In fact, patients with stage Ia NSCLC showed a 5-year survival rate of $84.5 \%$ in McKenna's series, ${ }^{28}$ which compares favorably with historical series of lobectomy by thoracotomy. Moreover, Mun and Kohno reported an actuarial survival rate in Japan of $76.4 \%$ at 3 years and $65.9 \%$ at 5 years, in their series of 55 octogenarian patients who underwent VATS resection for stage I lung cancer. The operative mortality was very reasonable $(3.6 \%)$, and 45 out of the 55 patients underwent an anatomic resection. ${ }^{29}$ Pagni and colleagues, at the Hospital of St Raphael in New Haven, Connecticut, compared 385 elderly patients $(>70)$ and found the mortality to be $4.2 \%$, compared to $1.6 \%$ in the control group $(<69)$. This series included sublobar/lobar resections, and pneumonectomies. The mortality in octogenarians was $2.8 \%$, and the authors found that female gender was an independent variable associated with decreased risk of death. The authors concluded that age remained a risk factor for overall mortality, and cautioned that pneumonectomy should be undertaken cautiously in this age group. ${ }^{30}$

In addition to the other factors mentioned earlier (comorbidities, performance status, and life expectancy), this leads us to discuss another relevant issue in the surgical treatment of elderly patients with NSCLC: the extent of surgery. While lobectomy has remained the standard surgical treatment of early-stage lung cancer since the Lung Cancer Study Group trial was published in the mid-90s, sublobar resection (wedge resection or segmentectomy) is currently more commonly performed, especially in patients with limited pulmonary reserve. ${ }^{31}$ This directly pertains to the elderly patient, and was examined by Mery and colleagues, who investigated the surgical outcomes from the Surveillance, Epidemiology, and End Results database. They found that age was an independent predictor of postsurgical survival in NSCLC, and that patients aged $\geq 75$ years exhibited similar overall survival, whether they received a lobectomy or a more limited resection. $^{32}$

On the other spectrum, patients with more advanced stage NSCLC often require more extended surgery, and/or multimodality treatment, involving chemotherapy and radiation therapy. While surgery remains debatable in stage IIIa disease in general, older patients represent a particular and undeniable treatment challenge in advanced stage NSCLC, due to obvious underlying comorbidities and potentially to a limited functional reserve. Even if technically feasible, pneumonectomy, for instance, has been associated with higher perioperative morbidity and mortality in the older population. In fact, Mizushima et al reported a $22 \%$ mortality rate in patients over 70 who had undergone a pneumonectomy $(6 / 27)$, compared to $3.2 \%$ in the younger group (3/95). ${ }^{33}$ Reflecting the importance of the pathological stage and the associated comorbidities, a contemporary Italian multiinstitutional series of lung resections in patients 75 years and older found that chronic renal failure, low respiratory reserve, and pneumonectomy were predictors of in-hospital mortality. While the overall survival at 1, 3, and 5 years was respectively $86 \%, 59 \%$, and $38 \%$, long-term overall survival was negatively influenced by pneumonectomy, extended resection, N1-2 subgroups, and a pathological tumor, node, metastasis, or TNM, stage. ${ }^{34}$

These reports underline the importance of careful selection of older patients to undergo more extensive surgery, in order to achieve acceptable outcomes in the treatment of advanced stage NSCLC. 


\section{Chemotherapy}

Chemotherapy alone has a limited role in the primary treatment of lung cancer. Although used as monotherapy in cases of metastatic disease, it is uncommon that chemotherapy is chosen as the sole treatment in potentially curable lung cancer. Combination chemoradiation may be chosen as a definitive treatment modality for stage II and III NSCLC tumors. However, it is most commonly used in patients with surgically unresectable stage IIIa disease. When used for definitive treatment of stage III disease, the greatest response is seen with concurrent therapy, where both the chemotherapy and radiation are delivered in a near-simultaneous manner. ${ }^{35}$ Unfortunately, just as concurrent therapy is more effective at treating the tumor, it is also associated with higher toxicity. For patients at higher risk for toxicities, sequential therapy is appropriate to consider. ${ }^{35}$

Despite the fact that the median age for NSCLC diagnosis is over the age of 70, this group is frequently underrepresented in chemotherapy trials. ${ }^{2}$ Thus, the treatment of older patients with lung cancer remains a difficult question that has yet to be answered. What is clear is that age remains a major influence in choosing whether to pursue adjuvant therapy, and surgeons are less likely to refer elderly patients for chemotherapy after surgery. This is likely a consequence of a number of factors that are listed in Table 2.

Data supporting adjuvant chemotherapy in the elderly is in fact limited. Many studies limit entry based on advanced age; additionally, there is a lack of interest among the elderly in receiving chemotherapy. This further limits acquiring data in this group of patients. One report published in 2007 found that patients older than 65 were less likely to complete treatment and received less chemotherapy, compared to the same patients under the age of $65 .{ }^{36}$ This study also reported that older patients derived significant benefit from the adjuvant

Table 2 Factors that may influence clinicians to minimize chemotherapy in elderly patients

\begin{tabular}{ll}
\hline Factors & $\begin{array}{l}\text { Group potentially } \\
\text { influenced by factors }\end{array}$ \\
\hline $\begin{array}{ll}\text { I. Misconception regarding normal } \\
\text { life expectancy in elderly patients }\end{array}$ & $\begin{array}{l}\text { Surgeon, oncologist, } \\
\text { patient, family } \\
\text { Surgeon, oncologist }\end{array}$ \\
$\begin{array}{l}\text { 2. Misconception regarding quality of life } \\
\text { 3. Lack of understanding of chemotherapy } \\
\text { modification affecting tolerance } \\
\text { (by nonmedical oncologist) }\end{array}$ & $\begin{array}{l}\text { Physician other than } \\
\text { medical oncologist }\end{array}$ \\
$\begin{array}{l}\text { 4. Lack of interest among elderly patients } \\
\text { in receiving adjuvant therapy }\end{array}$ & Patient \\
$\begin{array}{l}\text { 5. Lack of outcome data, including } \\
\text { elderly patients }\end{array}$ & Oncologist \\
\hline
\end{tabular}

chemotherapy combination of vinorelbine and cisplatin, and did not have significantly increased risk of toxicity, hospitalization rates, or treatment deaths. The authors therefore concluded that adjuvant chemotherapy should not be withheld from elderly patients. Of note, though, was that they considered elderly patients to be those above 65 years of age. ${ }^{36}$ Most would agree that this is not an excessively old age to treat. Additionally, newer agents are being developed that are starting to show promise. Erlotinib has shown promising results in clinical trials, demonstrating a higher quality of life, improved symptoms, and improved survival when used as a second- or third-line treatment in advanced or metastatic NSCLC patients. ${ }^{37}$ Similarly, a phase I trial of crizotinib has shown benefits in anaplastic lymphoma kinase-positive NSCLC patients..$^{38}$ In both cases, further investigation and clinical trials are required.

Furthermore, the Lace meta-analysis evaluated multiple adjuvant chemotherapy trials and evaluated patients in three age groups $(<65,65-69$, and $>70$ years old $) .{ }^{39}$ While efficacy was comparable between the three groups, patients over 70 showed a nonsignificant trend toward greater toxicity, compared to the other groups; they were also less likely to receive the same initial dose, and were less likely to receive two or more cycles of chemotherapy. ${ }^{39}$

For patients who are candidates for adjuvant therapy but are considered too high risk for platinum-based therapy, single-agent therapy may be a reasonable alternative, and is currently under investigation. A recently published meta-analysis by Des Guetz et al analyzed the benefit-to-risk ratio of doublet chemotherapy versus single-agent therapy in patients more than 70 years of age with advanced NSCLC. ${ }^{40}$ The metaanalysis evaluated ten studies and included 2605 patients. Toxicity was found to be significantly more frequent in patients receiving doublets, compared to single-agent therapy. Doublet therapy was, however, found to significantly increase overall response rate, compared to single-agent therapy; but no difference was found in the 1 -year overall survival. ${ }^{40}$

In the postoperative setting, the ability of a patient to tolerate adjuvant chemotherapy regardless of their age is important. Multiple publications have demonstrated the importance of successfully delivering complete regimens of adjuvant chemotherapy after surgery. ${ }^{41,42}$ It is generally accepted that since the introduction of minimally invasive thoracoscopic surgery, recovery and return to normal life has been improved, when compared with open thoracotomy. Although some have questioned the oncologic benefits of thoracoscopic surgery, these claims remain largely unsupported. One clear benefit of thoracoscopic pulmonary resection is 
the apparent increased ability to successfully deliver chemotherapy. In 2007, Petersen et al published a study evaluating adjuvant chemotherapy delivery following thoracoscopic lobectomy versus lobectomy by thoracotomy. They found that VATS was associated with a higher compliance rate, fewer delays, and fewer reduced doses of chemotherapy, compared to thoracotomy patients. ${ }^{43}$

\section{Radiation}

Radiation therapy in various forms has been a staple of cancer treatment for both inoperable and surgical oncological cases since the early $1900 \mathrm{~s} .{ }^{44}$ Stereotactic body radiation therapy (SBRT), also known as stereotactic ablative radiotherapy, is advocated for patients with stage I NSCLC who are elderly and/or medically unfit. ${ }^{45-49}$ In fact, many elderly patients have multiple other comorbidities, often rendering them to be high-risk surgical candidates. Case selection should occur in a multidisciplinary tumor board with dedicated thoracic surgeons, radiation oncologists, pulmonologists, pathologists, and radiologists, where the suitability of SBRT or resection should be considered. Conventional radiation therapy (RT) typically requires patients to travel for 5-7 weeks, which makes this treatment modality cumbersome and decreases the compliance rate. On the other hand, SBRT requires 1-5 treatments, and a survival benefit in patients 75 years or older has been demonstrated for SBRT over observation alone. ${ }^{46}$ SBRT generally involves a linear accelerator (Linac)-based technique using multiple (typically $>10$ ) noncoplanar, nonoverlapping radiation beams to deliver a high (tumoricidal) dose of radiation tightly conformed around the tumor target, while maximally sparing radiation exposure to adjacent normal tissues such as the healthy lungs, heart, esophagus, etc. ${ }^{46-50}$ There are various technologies used to perform SBRT; some of the more common include the Linac-based techniques Cyberknife ${ }^{\circledR}$ tomotherapy, and proton therapy.

Notably, SBRT has shown much greater efficacy than RT, with control rates rivaling those of lobectomy series. ${ }^{47-49}$ In fact, the local control rates in patients treated with SBRT are around 90\%-95\%, or even higher, in most series at 2-3-year follow-up intervals, versus $30 \%-50 \%$ with conventional RT. ${ }^{47-49}$ The survival rates with SBRT are $40 \%-60 \%$ at $2-3$ years, even in a group of medically inoperable patients with typically significant medical comorbidities. ${ }^{47-49}$ SBRT is relatively very well tolerated, with minor toxicities that include fatigue, skin irritation, and low-grade radiation pneumonitis. ${ }^{47-49}$ Even central tumors can be safely treated with good control using gentler dose fractionation schedules of SBRT. ${ }^{51}$
The risk of serious side effects; ie, debilitating radiation pneumonitis, tracheoesophageal fistula, bronchomalacia, hemoptysis, etc, is very low when performed at experienced radiation centers. ${ }^{47-49,51}$ SBRT is a highly specialized technique that requires the utmost attention to all aspects of treatment planning, and delivery, including patient selection, reproducible comfortable immobilization of patients, accounting for respiratory motion, a multitude of dose and volume constraints for both tumor and normal tissues in radiation-dose planning, appropriate dose prescription, image guidance for accurate verification of the target, and accurate treatment delivery while monitoring and ensuring accurate patient/target positioning. ${ }^{50,51}$ Indeed, the success of SBRT has prompted ongoing randomized Phase III trials, STARS and ROSEL studies of SBRT versus standard surgery for patients with medically operable stage I NSCLC. ${ }^{52-54}$

For elderly patients with more advanced, stages II and III, NSCLC, the options of surgery, radiation, and chemotherapy, or more commonly a combined multimodality approach. Relatively fit elderly patients should be considered for the same therapy as younger patients and have similiar expectations when considering efficacy, toxicity, and survival. ${ }^{55-58}$ For patients who are not candidates for surgery, radiation therapy and chemotherapy are viable options. ${ }^{55-58}$ However, when patients are not surgical candidates due to significant comorbidities, concurrent chemoradiation may also be intolerable, due to greater toxicity, and thus, caution is advised in these cases. ${ }^{55-58}$ Many such patients, however, would tolerate sequential chemotherapy and radiation, or radiation or chemotherapy alone. ${ }^{55-58}$ Moreover, survival seems better when definitive rather than palliative doses of radiation are used. ${ }^{58}$ Typically, chemotherapy is used before radiation in the sequential approach, but radiation can be used initially for patients with tracheabronchial or superior vena cava obstruction, hemoptysis, chest pain, or other local symptoms, with later consideration for systemic therapy. ${ }^{59,60}$

In stage IV NSCLC, treatment options in the elderly patient depend mainly on performance status and comorbid conditions, level of disease burden, and sites and symptoms of metastases. Systemic therapy is the primary treatment, but radiation therapy can be effective in palliating local symptoms due to tumors causing bronchial obstruction, superior vena cava compression, hemoptysis, chest pain, bony pain or threatening fracture, spinal epidural disease or cord compression, brain metastases, etc. ${ }^{59,60}$ SBRT can also be used in the treatment of oligometastatic disease. ${ }^{61}$

For elderly patients with one to three brain metastases, treatment options include surgery and/or whole brain 
radiation therapy (WBRT), and/or stereotactic radiosurgery (SRS), ${ }^{62-67}$ depending on performance status, status of primary disease, level of systemic disease burden, size and location of metastases, and presence or absence of neurological symptoms after implementation of steroids. ${ }^{62-67}$ SRS is a noninvasive technique shown to have relatively excellent safety and efficacy, with control rates typically ranging around $75 \%-90 \%{ }^{62-67} \mathrm{SRS}$ alone is increasingly being used in place of surgery at specialized centers, and can provide similar local tumor control and survival rates. ${ }^{62-67}$ Although the addition of WBRT to SRS, compared to SRS alone, reduces brain recurrences, there is no clear survival benefit, and thus many patients elect, to undergo SRS alone, and to avoid or delay WBRT, with its associated neurocognitive impact. ${ }^{62-67}$ Therefore, SRS alone as an upfront strategy can avoid or delay the toxicity of both surgery and WBRT, and achieve similar tumor control and survival outcomes with appropriate salvage treatment, if and when disease progression is noted upon close monitoring of serial brain magnetic resonance imaging. ${ }^{62-67}$

Similar to SBRT, SRS also delivers a high (tumoricidal) dose of radiation very tightly conformed around the tumor target. SRS can be performed with appropriate Linac-based technology, Gamma-knife ${ }^{\circledR}$, Cyberknife ${ }^{\circledR}$, tomotherapy, and proton beam therapy. Generally, tumors less than 3-4 cm are targeted with single-dose SRS, even though a few publications support hypofractionated (1-5 fractions) SRS in patients with larger tumors or tumors in unfavorable locations. ${ }^{68,69}$ When surgery is used, standard management includes adjuvant WBRT. However, an SRS boost to the surgical bed can be performed instead, with a similar outcome when patients are closely monitored. ${ }^{70}$ Whenever possible, a conservative (noninvasive) approach is favored in the elderly, with surgery reserved for metastases causing neurological symptoms or significant mass effects not improved by steroids, with comparable overall control rates and survival outcomes. ${ }^{62-67}$ For elderly patients with four or more brain metastases, treatment options include WBRT or best supportive care. In these patients, using SRS to target only a select few number of metastases, which are causing or likely to cause symptoms in the near future, can be considered for patients refusing or not likely to tolerate WBRT.

\section{Conclusion}

Lung cancer treatment in the elderly is increasingly common and a challenging concern for physicians. As the population continues to age and medical advances continue to increase life expectancy, physician care for the elderly patient with
NSCLC will become more common. Many factors influence care for the elderly, including our own experiences, biases, and misconceptions as they relate to age, quality of life, and life expectancy. Identifying and evaluating these factors is essential for avoiding these pitfalls, and is critical to providing the best care to these patients.

It is important for physicians involved in the management of NSCLC to be familiar with the various options for treatment and support. The use of multidisciplinary lung cancer programs to help integrate all of the specialties involved in NSCLC can avert undertreatment of the elderly. Continued research to optimize pulmonary resections and chemoradiation regimens is required, and future alternatives need to be explored in this patient population if we are to improve outcomes. Although important, age alone should not influence evaluation, management, or treatment of NSCLC in the elderly.

\section{Disclosure}

The authors report no conflicts of interest in this work.

\section{References}

1. Institute NC. Global Cancer Research Programs. cancer.gov. Accessed November 28, 2012

2. Institure NC. Surveillance Epidemiology and End Results. seer.cancer. gov. Accessed November 28, 2012.

3. Nations U. Population Ageing and Development. New York: Department of Economic and Social Affaris 2009.

4. Commerce USDo. United States 2010 Census 2010; http://www.census. gov/2010census/.

5. Arias E. United States life tables, 2007. National vital statistics reports : from the Centers for Disease Control and Prevention, National Center for Health Statistics, National Vital Statistics System. Sep 28, 2011;59(9):1-60.

6. Leonard RC, Barrett-Lee PJ, Gosney MA, Willett AM, Reed MW, Hammond PJ. Effect of patient age on management decisions in breast cancer: consensus from a national consultation. The oncologist. 2010;15(7):657-664.

7. Kassam F, Shepherd FA, Johnston M, et al. Referral patterns for adjuvant chemotherapy in patients with completely resected non-small cell lung cancer. Journal of thoracic oncology: official publication of the International Association for the Study of Lung Cancer. Jan 2007;2(1):39-43.

8. Kang KM, Jeong BK, Ha IB, et al. Concurrent chemoradiotherapy for elderly patients with stage III non-small cell lung cancer. Radiation oncology journal. Sep 2012;30(3):140-145.

9. Guckenberger M, Kavanagh A, Partridge M. Combining advanced radiotherapy technologies to maximize safety and tumor control probability in stage III non-small cell lung cancer. Strahlentherapie und Onkologie: Organ der Deutschen Rontgengesellschaft ... [et al]. Oct 2012;188(10):894-900.

10. Suda K, Tomizawa K, Mizuuchi H, et al. Genetic and Prognostic Differences of Non-small Cell Lung Cancer between Elderly Patients and Younger Counterparts. Aging and disease. Dec 2012;3(6):438-443.

11. Brandfonbrener M, Landowne M, Shock NW. Changes in cardiac output with age. Circulation. Oct 1955;12(4):557-566.

12. Gerstenblith G, Lakatta EG, Weisfeldt ML. Age changes in myocardial function and exercise response. Prog Cardiovasc Dis. Jul-Aug 1976;19(1):1-21.

13. Boss GR, Seegmiller JE. Age-related physiological changes and their clinical significance. West J Med. Dec 1981;135(6):434-440. 
14. Bader H. Dependence of wall stress in the human thoracic aorta on age and pressure. Circ Res. Mar 1967;20(3):354-361.

15. Carrick-Ranson G, Hastings JL, Bhella PS, et al. The Effect of Age-related Differences in Body Size and Composition on Cardiovascular Determinants of VO2 max. J Gerontol A Biol Sci Med Sci. Nov 15, 2012.

16. Cardus J, Burgos F, Diaz O, et al. Increase in pulmonary ventilationperfusion inequality with age in healthy individuals. Am J Respir Crit Care Med. Aug 1997;156(2 Pt 1):648-653.

17. DeLorey DS, Babb TG. Progressive mechanical ventilatory constraints with aging. Am J Respir Crit Care Med. Jul 1999;160(1):169-177.

18. Knudson RJ, Clark DF, Kennedy TC, Knudson DE. Effect of aging alone on mechanical properties of the normal adult human lung. J Appl Physiol. Dec 1977;43(6):1054-1062.

19. Castleden CM, George CF. The effect of ageing on the hepatic clearance of propranolol. Br J Clin Pharmacol. Jan 1979;7(1):49-54.

20. Fliser D, Franek E, Joest M, Block S, Mutschler E, Ritz E. Renal function in the elderly: impact of hypertension and cardiac function. Kidney Int. Apr 1997;51(4):1196-1204.

21. Weiss W. Operative mortality and five year survival rates in patients with bronchogenic carcinoma. American journal of surgery. Dec 1974;128(6):799-804.

22. Ginsberg RJ, Hill LD, Eagan RT, et al. Modern thirty-day operative mortality for surgical resections in lung cancer. The Journal of thoracic and cardiovascular surgery. Nov 1983;86(5):654-658.

23. Wada H, Nakamura T, Nakamoto K, Maeda M, Watanabe Y. Thirtyday operative mortality for thoracotomy in lung cancer. The Journal of thoracic and cardiovascular surgery. Jan 1998;115(1):70-73.

24. Kaseda S, Aoki T, Hangai N, Shimizu K. Better pulmonary function and prognosis with video-assisted thoracic surgery than with thoracotomy. The Annals of thoracic surgery. Nov 2000;70(5):1644-1646.

25. Landreneau RJ, Hazelrigg SR, Mack MJ, et al. Postoperative pain-related morbidity: video-assisted thoracic surgery versus thoracotomy. The Annals of thoracic surgery. Dec 1993;56(6):1285-1289.

26. Sugiura H, Morikawa T, Kaji M, Sasamura Y, Kondo S, Katoh H. Long-term benefits for the quality of life after video-assisted thoracoscopic lobectomy in patients with lung cancer. Surgical laparoscopy, endoscopy and percutaneous techniques. Dec 1999;9(6):403-408.

27. Jaklitsch MT, DeCamp MM, Jr, Liptay MJ, et al. Video-assisted thoracic surgery in the elderly. A review of 307 cases. Chest. Sep 1996;110(3):751-758.

28. McKenna RJ, Jr, Houck W, Fuller CB. Video-assisted thoracic surgery lobectomy: experience with 1,100 cases. The Annals of thoracic surgery. Feb 2006;81(2):421-425; discussion 425-426.

29. Mun M, Kohno T. Video-assisted thoracic surgery for clinical stage I lung cancer in octogenarians. The Annals of thoracic surgery. Feb 2008;85(2):406-411.

30. Pagni S, McKelvey A, Riordan C, Federico JA, Ponn RB. Pulmonary resection for malignancy in the elderly: is age still a risk factor? European journal of cardio-thoracic surgery: official journal of the European Association for Cardio-thoracic Surgery. Jul 1998;14(1):40-44; discussion 44- 45 .

31. Ginsberg RJ, Rubinstein LV. Randomized trial of lobectomy versus limited resection for T1 N0 non-small cell lung cancer. Lung Cancer Study Group. The Annals of thoracic surgery. Sep 1995;60(3):615-622; discussion 622-613.

32. Mery CM, Pappas AN, Bueno R, et al. Similar long-term survival of elderly patients with non-small cell lung cancer treated with lobectomy or wedge resection within the surveillance, epidemiology, and end results database. Chest. Jul 2005;128(1):237-245.

33. Mizushima Y, Noto H, Sugiyama S, et al. Survival and prognosis after pneumonectomy for lung cancer in the elderly. The Annals of thoracic surgery. Jul 1997;64(1):193-198.

34. Dell'amore A, Monteverde M, Martucci N, et al. Early and long-term results of pulmonary resection for non-small-cell lung cancer in patients over 75 years of age: a multi-institutional study. Interactive cardiovascular and thoracic surgery. Nov 23, 2012.
35. Johnson DH, Turrisi AT, Chang AY, et al. Alternating chemotherapy and twice-daily thoracic radiotherapy in limited-stage small-cell lung cancer: a pilot study of the Eastern Cooperative Oncology Group. Journal of clinical oncology: official journal of the American Society of Clinical Oncology. May 1993;11(5):879-884.

36. Pepe C, Hasan B, Winton TL, et al. Adjuvant vinorelbine and cisplatin in elderly patients: National Cancer Institute of Canada and Intergroup Study JBR.10. Journal of clinical oncology: official journal of the American Society of Clinical Oncology. Apr 20, 2007;25(12):1553-1561.

37. Gridelli C, Bareschino MA, Schettino C, Rossi A, Maione P, Ciardiello F. Erlotinib in non-small cell lung cancer treatment: current status and future development. The oncologist. Jul 2007;12(7):840-849.

38. Camidge DR, Bang YJ, Kwak EL, et al. Activity and safety of crizotinib in patients with ALK-positive non-small-cell lung cancer: updated results from a phase 1 study. The lancet oncology. Oct 2012;13(10):1011-1019.

39. Fruh M, Rolland E, Pignon JP, et al. Pooled analysis of the effect of age on adjuvant cisplatin-based chemotherapy for completely resected non-small-cell lung cancer. Journal of clinical oncology : official journal of the American Society of Clinical Oncology. Jul 20 2008;26(21):3573-3581.

40. Des Guetz G, Uzzan B, Nicolas P, Valeyre D, Sebbane G, Morere JF. Comparison of the efficacy and safety of single-agent and doublet chemotherapy in advanced non-small cell lung cancer in the elderly: A meta-analysis. Crit Rev Oncol Hematol. Apr 232012.

41. Bonadonna G, Valagussa P, Moliterni A, Zambetti M, Brambilla C. Adjuvant cyclophosphamide, methotrexate, and fluorouracil in nodepositive breast cancer: the results of 20 years of follow-up. $N$ Engl $J$ Med. Apr 6 1995;332(14):901-906.

42. Wick W, Hartmann C, Engel C, et al. NOA-04 randomized phase III trial of sequential radiochemotherapy of anaplastic glioma with procarbazine, lomustine, and vincristine or temozolomide. Journal of clinical oncology: official journal of the American Society of Clinical Oncology. Dec 10, 2009;27(35):5874-5880.

43. Petersen RP, Pham D, Burfeind WR, et al. Thoracoscopic lobectomy facilitates the delivery of chemotherapy after resection for lung cancer. The Annals of thoracic surgery. Apr 2007;83(4):1245-1249; discussion 1250 .

44. Alliance RT. Brief History of Radiation Therapy. http://www.radiationtherapyalliance.org/history. Accessed March 1, 2012.

45. Senan S, Palma DA, Lagerwaard FJ. Stereotactic ablative radiotherapy for stage I NSCLC: Recent advances and controversies. J Thorac Dis. Sep 2011;3(3):189-196.

46. Palma D, Visser O, Lagerwaard FJ, Belderbos J, Slotman BJ, Senan S. Impact of introducing stereotactic lung radiotherapy for elderly patients with stage I non-small-cell lung cancer: a population-based time-trend analysis. Journal of clinical oncology : official journal of the American Society of Clinical Oncology. Dec 10, 2010;28(35):5153-5159.

47. Timmerman R, Paulus R, Galvin J, et al. Stereotactic body radiation therapy for inoperable early stage lung cancer. JAMA. Mar 17, 2010;303(11):1070-1076

48. Onishi H, Shirato H, Nagata Y, et al. Stereotactic body radiotherapy (SBRT) for operable stage I non-small-cell lung cancer: can SBRT be comparable to surgery? Int J Radiat Oncol Biol Phys. Dec 1, 2011;81(5):1352-1358.

49. Baumann P, Nyman J, Hoyer M, et al. Outcome in a prospective phase II trial of medically inoperable stage I non-small-cell lung cancer patients treated with stereotactic body radiotherapy. Journal of clinical oncology: official journal of the American Society of Clinical Oncology. Jul 10 2009;27(20):3290-3296.

50. Potters L, Kavanagh B, Galvin JM, et al. American Society for Therapeutic Radiology and Oncology (ASTRO) and American College of Radiology (ACR) practice guideline for the performance of stereotactic body radiation therapy. Int J Radiat Oncol Biol Phys. Feb 1 2010;76(2):326-332.

51. Nuyttens JJ, van der Voort van Zyp NC, Praag J, et al. Outcome of four-dimensional stereotactic radiotherapy for centrally located lung tumors. Radiother Oncol. Mar 2012;102(3):383-387. 
52. Center MDAC. International randomized study to compare cyberknife stereotactic radiotherapy with surgical resection in stage I non-small cell lung cancer (STARS). Ongoing, updated on January 29, 2013, http:// clinicaltrials.gov/ct2/show/NCT00840749.

53. Center VUM. Trial of either surgery or stereotactic radiotherapy for early stage (IA) lung cancer (ROSEL). Not Currently Active, http:// clinicaltrials.gov/ct2/show/NCT00687986.

54. Das M, Abdelmaksoud MH, Loo BW, Jr., Kothary N. Alternatives to surgery for early stage non-small cell lung cancer-ready for prime time? Curr Treat Options Oncol. Jun 2010;11(1-2):24-35.

55. Atagi S KM, Yokoyama A, Okamoto H, et al. Japan Clinical Oncology Group Lung Cancer Study Group. Thoracic radiotherapy with or without daily low-dose carboplatin in elderly patients with non-small-cell lung cancer: a randomised, controlled, phase 3 trial by the Japan Clinical Oncology Group The lancet oncology. 2012;13(7):671-678.

56. Wisnivesky JP SG. Treating elderly patients with stage III NSCLC. The lancet oncology. 2012;13(7):659-651.

57. Coate LE, Massey C, Hope A, et al. Treatment of the elderly when cure is the goal: the influence of age on treatment selection and efficacy for stage III non-small cell lung cancer. Journal of thoracic oncology: official publication of the International Association for the Study of Lung Cancer. Mar 2011;6(3):537-544.

58. Wanders R, Steevens J, Botterweck A, et al. Treatment with curative intent of stage III non-small cell lung cancer patients of 75 years: a prospective population-based study. Eur J Cancer. Dec 2011;47(18):2691-2697.

59. Rodrigues G, Macbeth F, Burmeister B, et al. Consensus statement on palliative lung radiotherapy: third international consensus workshop on palliative radiotherapy and symptom control. Clinical lung cancer. Jan 2012;13(1):1-5.

60. Kepka L, Olszyna-Serementa M. Palliative thoracic radiotherapy for lung cancer. Expert Rev Anticancer Ther. Apr 2010;10(4):559-569.

61. Dahele M, Senan S. The role of stereotactic ablative radiotherapy for early-stage and oligometastatic non-small cell lung cancer: evidence for changing paradigms. Cancer Res Treat. Jun 2011;43(2):75-82.
62. Elaimy AL, Mackay AR, Lamoreaux WT, et al. Clinical outcomes of stereotactic radiosurgery in the treatment of patients with metastatic brain tumors. World Neurosurg. May-Jun 2011;75(5-6):673-683.

63. Den RB, Andrews DW. Combined role of whole-brain radiation therapy and radiosurgery for the treatment of brain metastasis. Prog Neurol Surg. 2012;25:228-235.

64. Marko NF, Suh JH, Chao ST, et al. Gamma knife stereotactic radiosurgery for the management of incidentally-identified brain metastasis from non-small cell lung cancer. J Neurooncol. Sep 2011;104(3):817-824.

65. Jenkinson MD, Haylock B, Shenoy A, Husband D, Javadpour M Management of cerebral metastasis: evidence-based approach for surgery, stereotactic radiosurgery and radiotherapy. Eur J Cancer. Mar 2011;47(5):649-655.

66. Park HS, Chiang VL, Knisely JP, Raldow AC, Yu JB. Stereotactic radiosurgery with or without whole-brain radiotherapy for brain metastases: an update. Expert Rev Anticancer Ther. Nov 2011;11(11):1731-1738.

67. Patil CG, Pricola K, Sarmiento JM, Garg SK, Bryant A, Black KL. Whole brain radiation therapy (WBRT) alone versus WBRT and radiosurgery for the treatment of brain metastases. Cochrane Database Syst Rev. 2012;9:CD006121.

68. Schlienger M, Nataf F, Huguet F, et al. [Hypofractionated stereotactic radiotherapy for brain metastases]. Cancer Radiother. Apr 2010;14(2):119-127.

69. Narayana A, Chang J, Yenice K, et al. Hypofractionated stereotactic radiotherapy using intensity-modulated radiotherapy in patients with one or two brain metastases. Stereotact Funct Neurosurg. 2007;85(2-3):82-87.

70. Robbins JR, Ryu S, Kalkanis S, et al. Radiosurgery to the surgical cavity as adjuvant therapy for resected brain metastasis. Neurosurgery. Nov 2012;71(5):937-943.
Drug, Healthcare and Patient Safety

\section{Publish your work in this journal}

Drug, Healthcare and Patient Safety is an international, peer-reviewed open-access journal exploring patient safety issues in the healthcare continuum from diagnostic and screening interventions through to treatment, drug therapy and surgery. The journal is characterized by the rapid reporting of reviews, original research, clinical, epidemiological and

\section{Dovepress}

post-marketing surveillance studies, risk management, health literacy and educational programs across all areas of healthcare delivery. The manuscript management system is completely online and includes a very quick and fair peer-review system. Visit http://www.dovepress.com/ testimonials.php to read real quotes from published authors. 